\title{
INVESTIGATION OF DEFECT EFFECTS ON ADHESIVELY BONDED JOINT STRENGTH USING COHESIVE ZONE MODELING
}

\author{
MAJID Jamal-Omidi ${ }^{1}$, MOHAMMAD REZA Mohammadi Suki ${ }^{1}$ \\ ${ }^{I}$ Malek-Ashtar University of Technology, Space Research Institute, Department of Aerospace Engineering, \\ Tehran, 15875-1774, Iran,e-mail: j_omidi@mut.ac.ir; m.r.mohammadi.suki@gmail.com
}

\begin{abstract}
In this paper, effects of the defect in an adhesively bonded joint have been investigated using cohesive zone modeling. Consequently, a 3D finite element model of a single lap-joint is constructed and validated with experiments. Strength prediction of current model is found desirable. Accordingly, different sizes of square shape defects are imported to model in the form of changing (raised or degraded) material properties (heterogeneity) and locally delaminated areas (as inclusion/void), respectively. Joint strength is investigated and a stress analysis is carried out for adhesive layer and adherends. Obtained Results show that, defect has significant impact on the results. It is found that at constant size of defect, local delamination has more impact on bonded joint strength than the heterogeneity. Furthermore, stress analyses demonstrate that the stress field does not change in adherends by taking defects into account. However, stress values decrease with degraded material properties and joint's strength. Through evaluation of peel and transverse shear stresses in adhesive layer it is found that there is a change of stress distribution for both types of defects. Whereas, there is a considerable stress concentration in the delaminated adhesive layer.
\end{abstract}

KEYWORDS: adhesively bonded joint, defect, cohesive zone modeling, strength prediction

\section{Introduction}

Due to the developments in adhesives' technologies and also their higher peel and shear strengths and ductility, the use of adhesive bonding in many fields of engineering, such as automotive and aeronautical engineering has become possible [1]. Since adhesively bonded joints brings several advantages over welding, riveting and bolting methods, such as reduction of stress concentrations, reduced weight penalty and easy manufacturing, they are often used in multi-component structures [2].

It is important to analyze and predict failure behavior of adhesive bonding in order to predict the performance and to improve reliable and safe joint designs. In the past, different approaches were employed to predict the mechanical behavior of bonded joints. At first, theoretical investigations of stress fields in the adhesive and failure prediction (by comparison of the maximum stresses with the material strengths) were popular because of simplicity and quickness. However, this approach employs lots of simplifying assumptions and can only be used for simple geometries [3-8].

In recent decades, finite element methods due to being highly accurate and combining several complex material laws have replaced theoretical methods in predicting adhesive mechanical behavior. Initially failure prediction of adhesive bonded joints was based on stress/strain criteria, which, has several drawbacks like dependence on the mesh size at the critical regions. Another finite element failure prediction is based on fracture mechanics criteria, such as the Virtual Crack Closure Technique (VCCT), which are bounded to Linear Elastic Fracture Mechanics (LEFM) and need an initial crack with a very fine mesh [9-11]. 
More recently, powerful numerical techniques such as Cohesive Zone Modeling (CZM) have become available. The CZM method has been used for analyzing adhesive joints. It overcomes the limitations of the aforementioned approaches such as requiring an initial crack, and also brings more accurate prediction than conventional finite element methods because different shapes of the cohesive laws can be employed. In order to implement CZM method, a traction-separation law with a pre-defined shape (e.g. exponential, trapezoidal, and the bilinear shape) should be used, also the values of critical energy release rate and cohesive strength respectively for damage initiation and evolution at failure region must be determined [12-16]. Moreover, techniques used for determining the cohesive strength and critical energy release rate, commonly are the property identification technique, the direct method and the inverse method. These methods are based on the Double Cantilever Beam (DCB) and End Notched Flexure (ENF) tests. The inverse method estimates the CZM parameters by iterative fitting the finite element result with experimentally measured data (the load-displacement curve) until an accurate representation achieved [12]. The CZM method depends on an accurate measurement of the cohesive strengths in tension and shears and of the critical energy release rates; therefore, accurate values of these parameters play a crucial role in accuracy of results. Experiments suggest that the greater the adhesive thickness, the higher the apparent critical fracture energy [17]. Other parameters affecting joint strength are overlap length, adherend materials and thickness [18].

One of the most important factors that affect the joint strength and makes the strength prediction difficult are adhesive defects. There is a lot of sources for induction of defects in the adhesive for instance; fabrication procedure, deficient joint preparation, micro-cracking, air bubbles, foreign bodies, grease, and dirt [19]. Existence of a defect in structural members such as plates and shells can make them weak. In fact, there is no or little (by degrading adhesive material properties) load transmission through the joints component in the defects sites which make the stress increase near the defects locally, hence, the joint strength reduces at overall [20]. Furthermore, appearance of such defects can bring unpredictable behaviors, consequently, causing weakness or even rapid total failure of adhesive joint. Therefore, there is a great need in understanding the defect effects in adhesively bonded joint behavior and strength, in order to determine whether a joint with a defect can operate properly in a period of time or not.

Maksimyuk et al. [21] studied redistribution of stress around the inclusion in plate members which were subjected to internal pressure. Stress concentrations around the inclusion in shells were investigated in many studies [22-25], there are some experimental [26-28] and theoretical [29-31] studies concerning adhesively bonded joints with defects. However, little attention has been paid to numerical study of defect effects on an adhesively bonded joint strength. A bonded plate assembly with a heterogeneous adhesive layer was investigated by Uysal and Güven [32]. They studied buckling loads for the adhesively bonded plates having elliptical inclusions. They found out that, the inclusion has great influence on the attained results. Prasad and Khantwal [33] studied the breaking load of single lap joint with different joining technique for alloy steel and mild steel. Based on the result, adhesive joint has the lowest breaking load and elongation compared to other joining technique.

In this study, a numerical model was established based on cohesive zone model to predict the failure behavior of adhesive joint and investigate the effects of defect on joint strength. Using finite element method, a single lap-joint model has been carried out and acquired results are compared with experimental results and numerical prediction available in literature. In order to study adhesively bonded joint defect effect on joint strength, the defect is taken into account as two different types; (1) locally inadequate bonding which is modeled as change of the adhesive properties and (2) void/inclusion which is considered as local 
delamination in different sizes in a single lap-joint. Finally, the results are evaluated and an elastic stress analysis is carried out. Some conclusions are established to understand the effects of defect in adhesive layer strength and provide important data for bonded joints designers. The main innovation of present work is to predict the strength of adhesive joint with defect and doing a stress and damage analysis and estimate the joint behavior using the CZM method utilizing a three-dimensional model.

\section{Cohesive Zone Model Theory}

It can be seen from Fig. 1, that cohesive zone model relates traction to separation at an interface where a crack may initiate. CZM simulates the elastic behavior up to a peak load and followed by a softening behavior, to model the progressive degradation of material properties up to complete failure. Therefore, the areas under the traction separation laws equal the fracture energy. In the present study, traction-separation laws using quadratic stress-based failure criteria and mixed-mode energy-based damage evolution are considered.

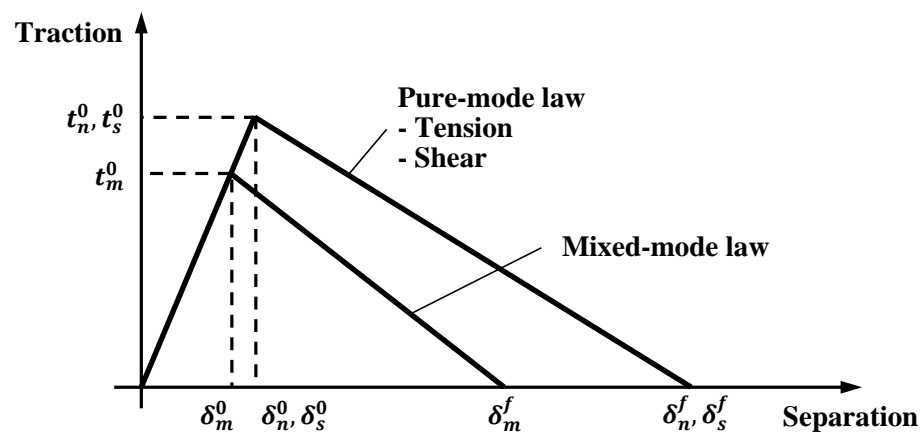

Fig. 1 Bi-linear traction separation law [15].

The traction-separation law assumes a linear elastic behavior followed by linear evolution of damage, and the slope of linear elastic range line is defined as the penalty stiffness $(K)$. Consequently, elasticity is defined by an elastic constitutive matrix relating the stresses and strains in tension and shears across the interface (subscripts $n, s$, and t, respectively) [34]:

$$
t=\left\{\begin{array}{l}
t_{n} \\
t_{s} \\
t_{t}
\end{array}\right\}=\left[\begin{array}{lll}
k_{n n} & k_{n s} & k_{n t} \\
k_{n s} & k_{s s} & k_{s t} \\
k_{n t} & k_{s t} & k_{t t}
\end{array}\right] \cdot\left\{\begin{array}{l}
\varepsilon_{n} \\
\varepsilon_{s} \\
\varepsilon_{t}
\end{array}\right\}=K \varepsilon
$$

Many researchers have considered formulas for calculating penalty stiffness. Turon [35] suggested a formula for calculating penalty stiffness:

$$
K=\frac{\alpha E_{3}}{h}, \text { where } K_{1}=K_{2}=K_{3}=K
$$

where $E_{3}$ is Young modulus, $h$ is the thickness of the adhered plies, $\alpha \gg 1$, with a suggested value of 50 and $K_{1}, K_{2}$ and $K_{3}$ are penalty stiffnesses in each mode of loading [35]. Also, Corigliano suggested following formula for penalty stiffness:

$$
K_{1}=\frac{2 G_{13}}{e}, \quad K_{2}=\frac{2 G_{23}}{e}, \quad K_{3}=\frac{E_{3}}{e}
$$

where $e$ is the thickness of adhesive and $G_{13}, G_{23}$ and $E_{3}$ are shear and Young moduli [36]. Camanho et al. [37] and Harper [38] respectively used a penalty stiffness of $K=10^{6} \mathrm{~N} / \mathrm{mm}^{3}$ and $K=10^{5} \mathrm{~N} / \mathrm{mm}^{3}$ in their studies and they reached good results. Damage initiation can be specified by different criteria. In this paper, quadratic stress-based failure criterion is selected for damage initiation. Quadratic stress-based failure criterion is as follows: 


$$
\left\{\frac{\left\langle t_{n}\right\rangle}{t_{n}^{0}}\right\}^{2}+\left\{\frac{\left\langle t_{s}\right\rangle}{t_{s}^{0}}\right\}^{2}+\left\{\frac{\left\langle t_{t}\right\rangle}{t_{t}^{0}}\right\}^{2}=1
$$

The Macaulay brackets in the equation (4) indicate that merely compressive stresses or deformations do not initiate damage. A variable, $D$, shows damage quality by changing from 0 (no damage) to 1 (complete failure), therefore:

$$
t_{n}=(1-D) \bar{t}_{n}, \quad t_{s}=(1-D) \bar{t}_{s}, t_{t}=(1-D) \bar{t}_{t}
$$

where $t_{n}, t_{s}$ and $t_{t}$ are stress components predicted by elastic behavior for current strains without damage. Damage evolution is assumed to be linear. After reaching cohesive strength, the adhesive stiffness degradation initiates and continues until full separation and maximum mixed mode failure displacement is reached. When a mixed-mode loading are present simultaneously, a mixed mode damage model is necessary. There is the linear form of the power law which predicts the required energies for failure in the pure modes as follows [34]:

$$
\frac{G_{I}}{G_{I C}}+\frac{G_{I I}}{G_{I I c}}+\frac{G_{I I I}}{G_{I I I C}}=1
$$

However, for single lap-joint, the amount of energy required for complete failure is secured from the Benzeggagh-Kenane (BK) mixed-mode equation which is particularly useful when the critical energy release rates during deformation purely along the first and the second shear directions are the same, and calculates the critical energy $\left(G_{c}\right)$ based on mixing modes $I$ and $I I$ fracture energies (see Fig. 2) [39]:

$$
G_{c}=G_{I c}+\left(G_{I I c}-G_{I c}\right)\left(\frac{G_{\text {shear }}}{G_{T}}\right)^{\eta}
$$

$G_{\text {shear }}=G_{I I}+G_{I I I}, G_{T}=G_{I}+G_{I I}+G_{I I I}$ and $\eta$ are BK material parameter. Cohesive zone modeling is based on two different techniques; cohesive element and surface based cohesive behavior. Surface based cohesive behavior offers capabilities that are very similar to cohesive elements that are defined using a traction-separation law. However, surface-based cohesive behavior is typically easier to define and allows simulation of a wider range of cohesive interactions, such as two "sticky" surfaces coming into contact during an analysis [34]. In this paper, surface based cohesive behavior has been used.

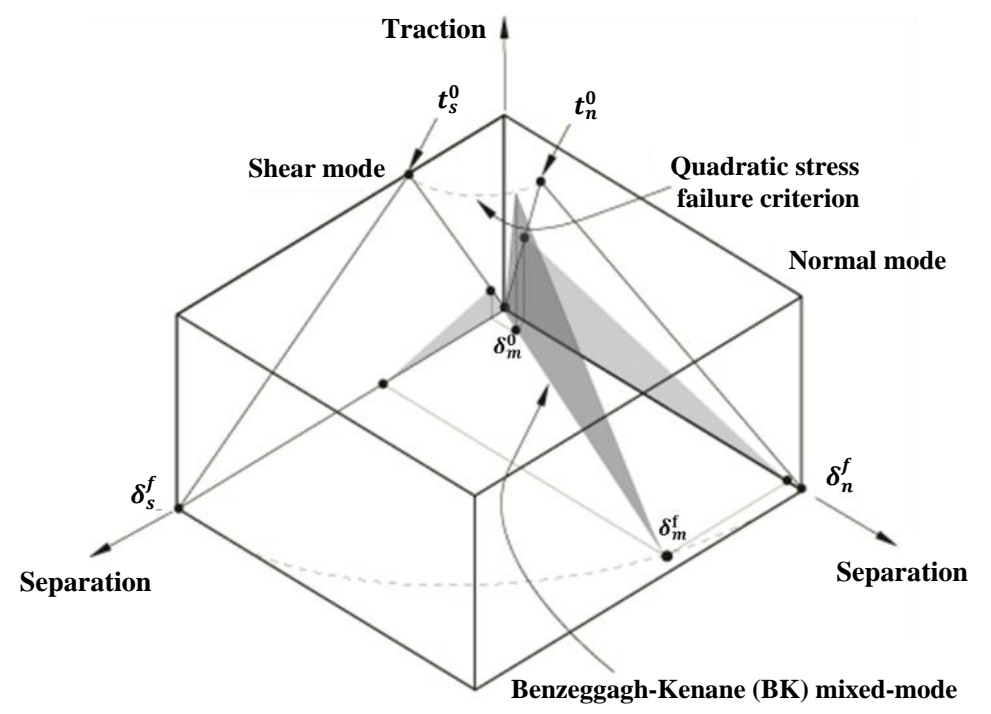

Fig. 2 Diagram of mixed-mode traction-separation model [34]. 


\section{$3 \quad$ Numerical Study}

\subsection{Numerical modelling of single lap-joint}

In order to simulate the adhesively bonded joints, the ABAQUS version 6.13 is used. Therefore, the finite element Simulation is performed by the solver ABAQUS/Standard. The bilinear CZM formulation is chosen for present work because of its simplicity, and availability in ABAQUS, also, a mixed mode formulation is utilized.

For investigating the defect effects on adhesively bonded joints, initially, a metal-metal single lap-joint finite element model, which is loaded under mixed-mode conditions, is constructed. The main reason is to validate the present model with experimental and numerical results presented by Anyfantis et al. [40, 41] and predict failure behaviour of the adhesive joint. Anyfantis et al. tested three specimens for single lap-joint under a tensile loading using a MTS hydraulic testing machine at room temperature under displacement control with a rate of $0.1 \mathrm{~mm} / \mathrm{min}$ [40,41]. Nevertheless, single lap-joint geometry is shown in Fig. 3 and width of the single lap-joint is $28.5 \mathrm{~mm}$. Adherends are mild marine steels which are modelled as typical elastic solids and C3D8R elements are utilized for them. The single lap-joint was modelled as three-dimensional and geometrical nonlinearities were considered. Adhesive layer is Araldite 2015 and adhesive thickness $\left(T_{a}\right)$ is $0.5 \mathrm{~mm}$. Adhesive layer is modelled using surface based cohesive behaviour (surfaces of overlap area), and bilinear CZM formulation, including a mixed-mode formulation has been employed for the description of their constitutive relation. Therefore, no elements are considered for adhesive layer and it is defined as part of the surface interaction properties that are assigned to a contact pair (surface of overlap area). Accordingly, the constructed finite element model is shown in Fig. 4.

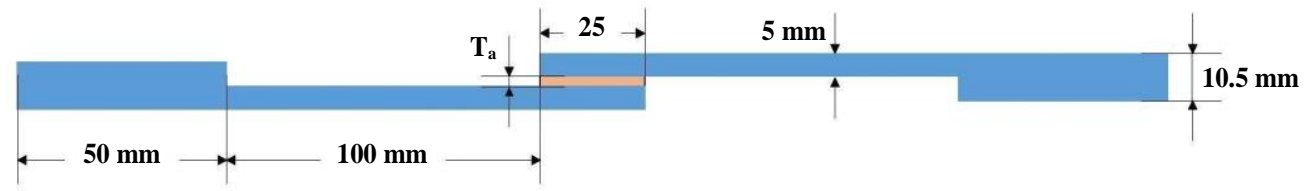

Fig. 3 Geometry of single lap-joint specimen.

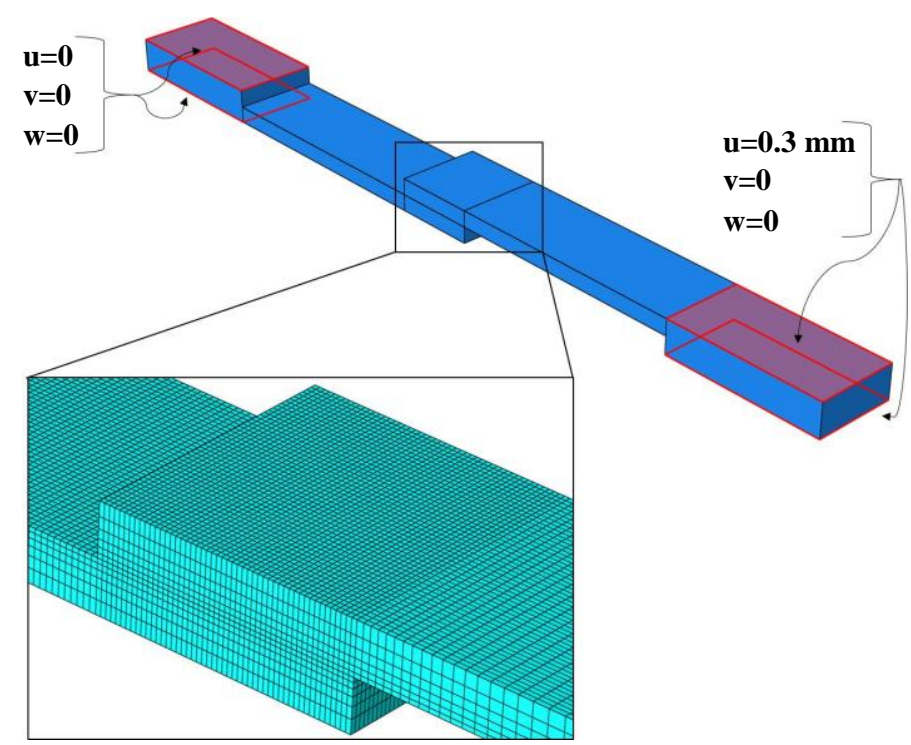

Fig. 4 Numerical modelling of single lap-joint test and boundary conditions. 
Anyfantis et al. [40] suggested a $0.5 \times 0.5 \mathrm{~mm}^{2}$ dimension for adhesive layer element size, hence, $0.5 \times 0.5 \mathrm{~mm}^{2}$ element dimension is considered for adjacent adherends at overlap area. For the sake of solving time and the computational effort, the elements are constructed using bias effects from the bonding area towards the edges of adherends. Loading and boundary conditions are faithful to real testing conditions and have been applied to areas of adherends that are restrained in grips of testing machine. As shown in Fig. 4, $0.3 \mathrm{~mm}$ tensile displacement is applied. Material properties of Aralidite 2015 is presented in Table 1, and penalty stiffnesses in different fracture modes are calculated by dividing elastic and shear moduli on adhesive thickness.

Table 1 Properties of the adhesive Araldite 2015 for single lap-joint simulation [40].

\begin{tabular}{ccc}
\hline Property & Unit & Value \\
\hline Young's modulus, $E$ & $\mathrm{GPa}$ & 1.85 \\
Shear modulus, $G$ & $\mathrm{GPa}$ & 0.7115 \\
$t_{n}^{0}$ & $\mathrm{MPa}$ & 30 \\
$t_{s}^{0}$ & $\mathrm{MPa}$ & 18.5 \\
$t_{t}^{0}$ & $\mathrm{MPa}$ & 18.5 \\
$G_{I c}$ & $\mathrm{~N} / \mathrm{mm}$ & 4.0 \\
$G_{I I c}$ & $\mathrm{~N} / \mathrm{mm}$ & 4.7 \\
$G_{I I I c}$ & $\mathrm{~N} / \mathrm{mm}$ & 4.7 \\
\hline
\end{tabular}

Experimentally gained and numerically predicted responses of single lap-joint are represented in Fig. 5. Single lap-joint response, is expressed in the form of applied force on adhesive layer to displacement of adherends. As shown, load-displacement curve consists of three fields. First one is linear from 0 to $0.1 \mathrm{~mm}$ displacement which adhesive is in elastic state. The second field corresponds to the damage initiation and load carrying capacity of adhesive layer at redirection of load-displacement curve. And the last field is damage evolution and softening behaviour of the adhesive layer where joint cannot bear any more load.

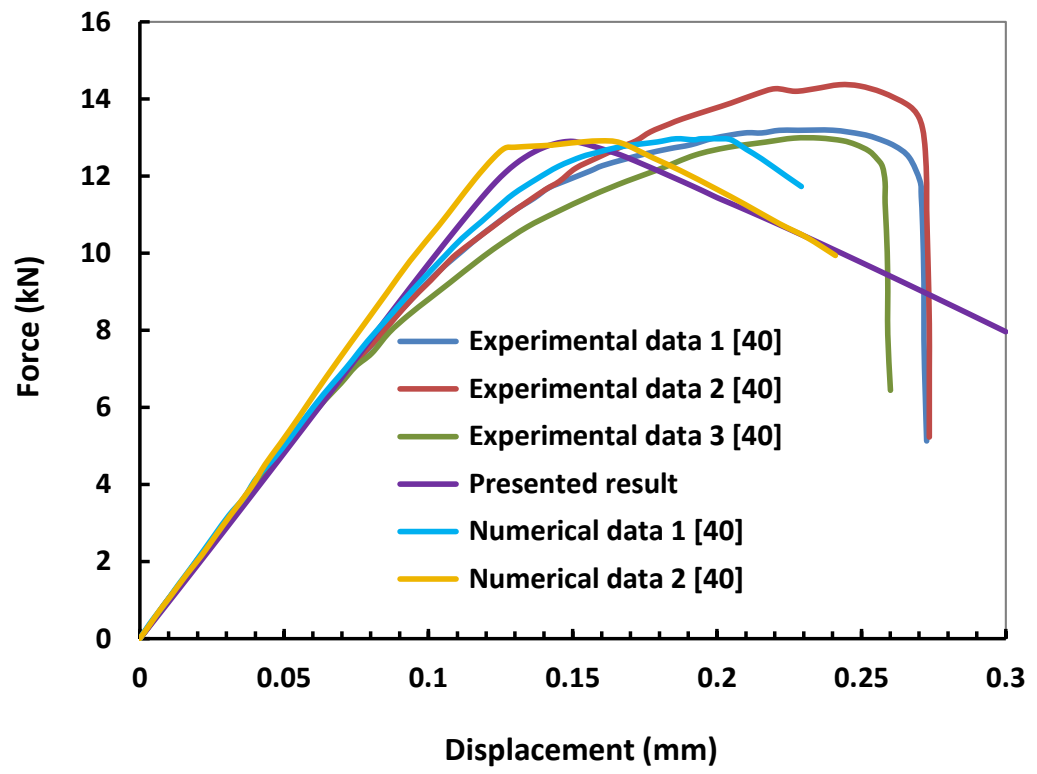

Fig. 5 Numerical and experimental load-displacement curves for present single lap-joint specimen.

Table 2 presents a comparison between present numerical and experimental results and numerical predictions by Anyfantis et al. [40] in terms of maximum load and deflection in 
maximum load values. All of numerical predictions have good agreement to experimental average values. Present work has respectively $4.15 \%$ and $37.75 \%$ differences for maximum load and displacement at maximum load to experimental average values. As can be seen in the figure, presented numerical result completely mimics the experimental result at elastic region. Although there is a variation in amount of maximum displacement and predicting softening behaviour, which result from numerical limitation of CZM law shape. Since the acquired curve follows the CZM law shaped used closely, there is an acceptable prediction of softening behaviour for present numerical simulation compared to experimental and numerical curves. The main aim of the present study is strength prediction and determination of load carrying capacity of the adhesive layer is fully acquired, moreover, it can be seen that present numerical is fairly acceptable compared to numerical data 2 . Therefore, overall accuracy of present numerical prediction is pleasant. Fig. 6 shows the von-Mises stress distribution in adherends at maximum applied load at the point of redirection of curve for present simulation.

Table 2 Comparison of obtained present FE results with available experimental and numerical data [40].

\begin{tabular}{ccccccc}
\hline \multirow{2}{*}{ Results } & \multicolumn{2}{c}{ Maximum Load } & & \multicolumn{2}{c}{ Deflection at Max. load } \\
\cline { 2 - 3 } & $\begin{array}{c}\text { Value } \\
(\mathrm{kN})\end{array}$ & $\begin{array}{c}\text { Error } \\
(\%)\end{array}$ & & $\begin{array}{c}\text { Value } \\
(\mathrm{mm})\end{array}$ & $\begin{array}{c}\text { Error } \\
(\%)\end{array}$ \\
\hline Experimental data 1 [40] & 13.2 & - & & 0.240 & - \\
Experimental data 2 [40] & 12.9 & - & & 0.237 & - \\
Experimental data 3 [40] & 14.3 & - & & 0.247 & - \\
Experimental average [40] & 13.47 & - & & 0.241 & - \\
Presented results & 12.91 & 4.15 & & 0.15 & 37.75 \\
Numerical data 1 [40] & 13.07 & 2.96 & & 0.199 & 17.42 \\
Numerical data 2 [40] & 12.90 & 4.23 & & 0.16 & 33.60 \\
\hline
\end{tabular}

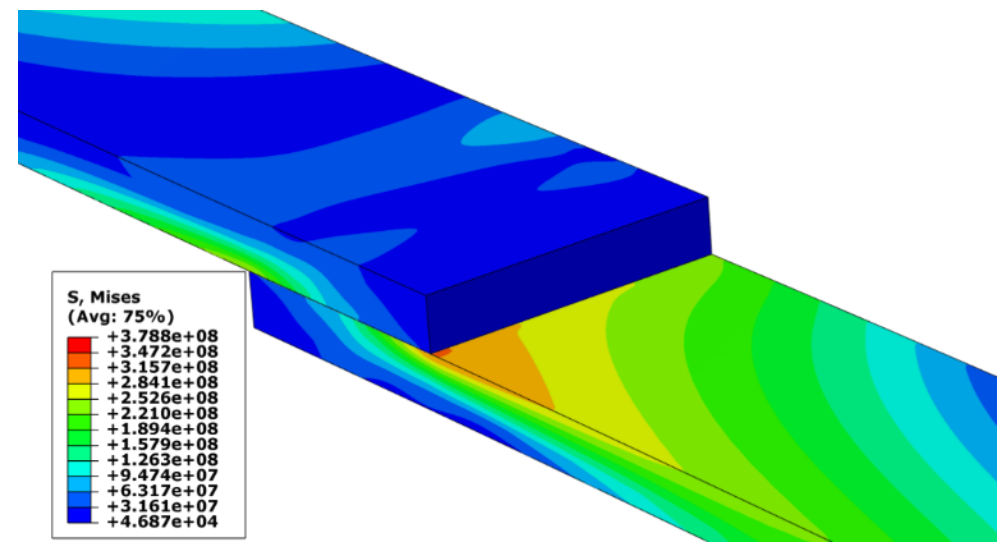

Fig. 6 Single lap-joint von-Mises stress distribution in adherends at maximum load.

\subsection{Numerical analyses of defect in adhesive layer}

In order to study the effect of defects in adhesive layer, defects have been presented as changing of material properties and delaminated area consequently. In the models defect is a square area at the center of adhesive layer in four different sizes. Araldite 2015 with $0.2 \mathrm{~mm}$ thickness and material properties presented in Table 1 is selected as adhesive layer. A single lap-joint with same modelling procedure as section 3.2 is constructed, however, for investigating the effect of defects in center of adhesive layer, model width change to $25 \mathrm{~mm}$ 
to make the overlap area square. As presented in Fig. 7, in order to introduce defect in the numerical models, four different sizes of $5 \times 5 \mathrm{~mm}^{2}$ (4\% of area), $8 \times 8 \mathrm{~mm}^{2}$ (10\% of area), $10 \times 10 \mathrm{~mm}^{2}\left(16 \%\right.$ of area) and $12 \times 12 \mathrm{~mm}^{2}$ (23\% of area) have been separated at the center of overlap area. A delaminated area in adhesive layer and a change of material properties as variations of separated adhesive layer material properties at the overlap area, in the form of a coefficient of cohesive strength and critical energy release rates. It should be noted that penalty stiffness is fixed for all models. Initially a perfect adhesively bonded single lap-joint is simulated and defective models' results are compared with it.

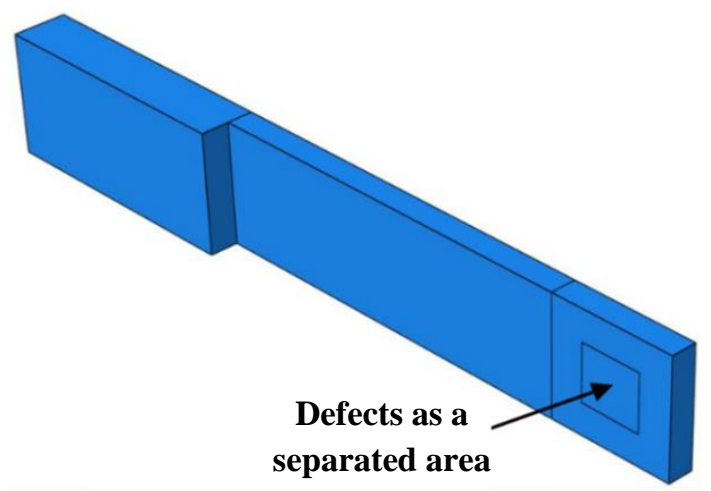

Fig. 7 An example of separated area in the center of overlap area which serves as defect.

\section{Results and Discussion}

\subsection{Numerical modelling of single lap-joint}

The obtained results are presented in Figs. 8 and 9 for different defects. As can be seen in Fig. 8, by enlarging the area of delamination, strength of adhesive reduces. Also, as shown in Fig. 9, by enlarging the size of changed material properties the change of strength gets more severe. Fig. 10 shows perfect single lap-joint and square shape defects load-displacement curves. On the other hand, Fig. 10 and Fig. 11 demonstrates that with fixed size and shape of the defect, local delamination has the most impact on joint strength as the joint strength weakening is severe.

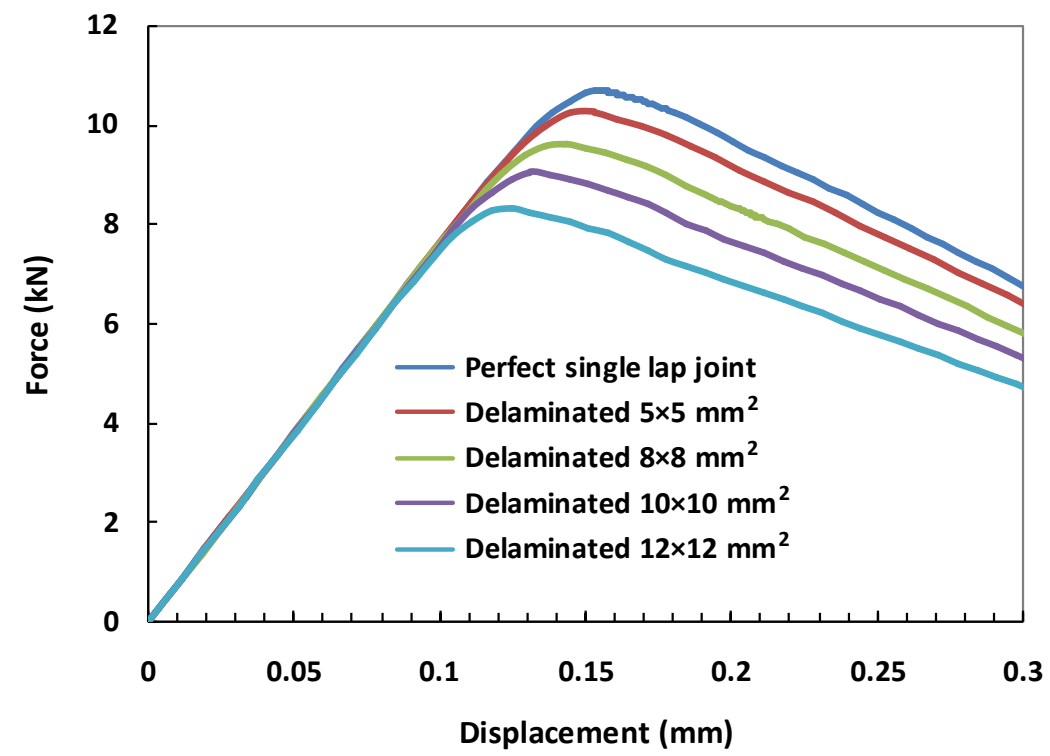

Fig. 8 Force-displacement curves for perfect single lap-joint and the model with delamination. 
A comparison of numerical results is shown in Table 3 and Fig. 11. It can be noted that as the size of delamination grows, highest load and deflection at peak load values decrease and compared to changed material properties (heterogeneous) model it has the most discrepancy with the perfect model. on the other hand, change of material properties from 1.2 times to 0.4 times of original material properties does not have too much difference with respect to the perfect model, for which, maximum discrepancy is about 5\%. Moreover, another interesting point is that discrepancy of maximum load and deflection at maximum load on the heterogeneous model from those acquired from perfect model is almost the same in every type.

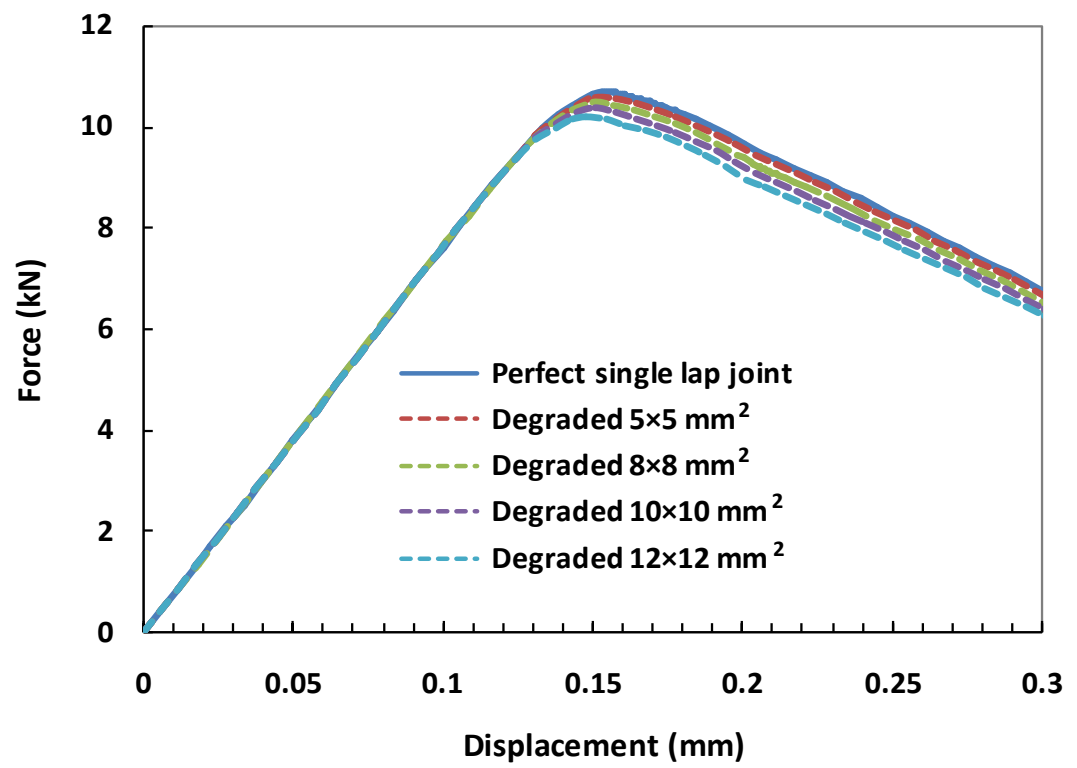

(a)

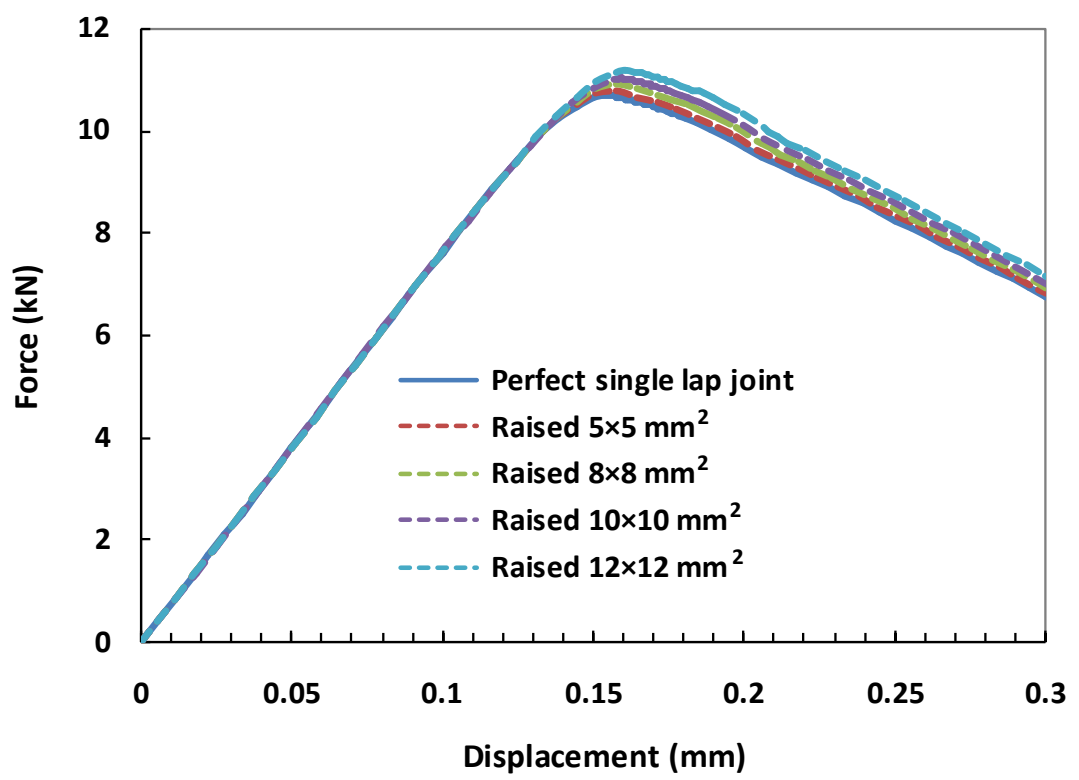

(b)

Fig. 9 Force-displacement curves for perfect single lap-joint and inhomogeneity in the form of (a) degradation ( 0.8 times) and (b) raising (1.2 times) of cohesive strength and critical energy release rates for different sizes. 


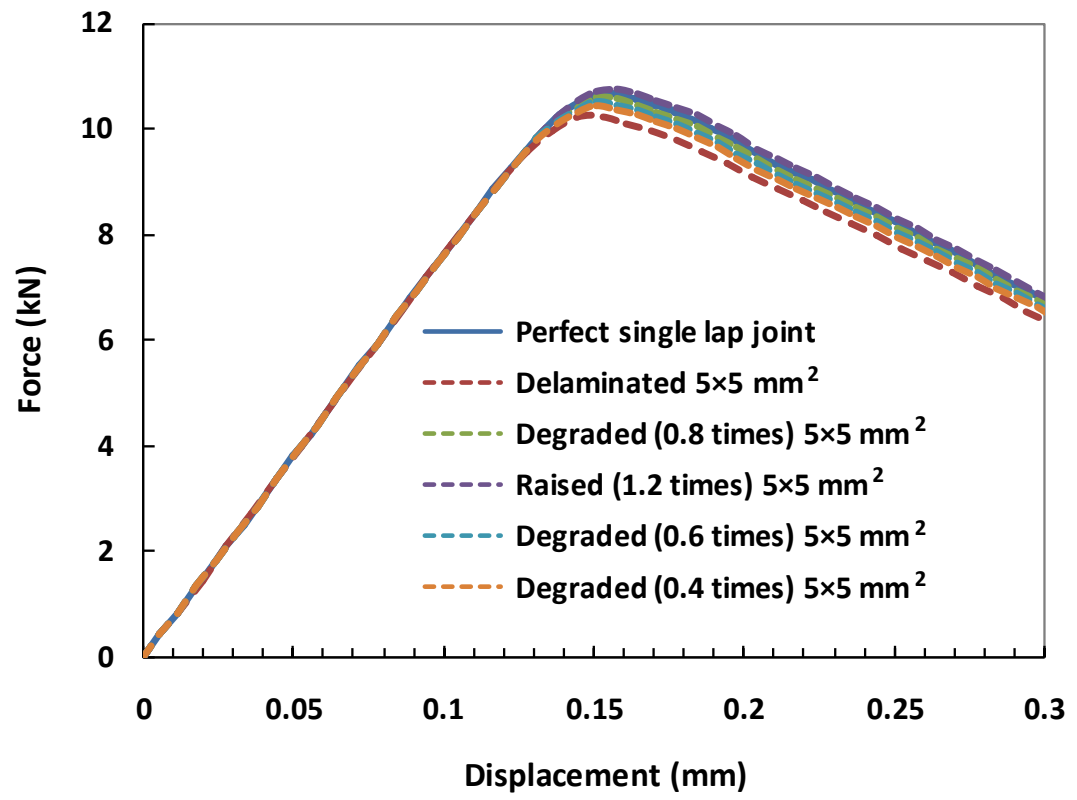

Fig. 10 Force-displacement curves for perfected single lap-joint and single lap-joints with a square of $5 \mathrm{~mm} 2$ at the center of overlap area for presenting inclusion and inhomogeneity in the form of delamination and raised or degraded cohesive strength and critical energy release rates.

Table 3 Comparison of obtained present finite element results.

\begin{tabular}{|c|c|c|c|c|c|}
\hline \multirow[b]{2}{*}{ Defect size } & \multirow[b]{2}{*}{ Type } & \multicolumn{2}{|c|}{ Maximum Load } & \multicolumn{2}{|c|}{ Deflection at max. load } \\
\hline & & $\begin{array}{l}\text { Value } \\
(\mathrm{kN})\end{array}$ & $\begin{array}{c}\text { Discrepancy } \\
(\%)\end{array}$ & $\begin{array}{l}\text { Value } \\
(\mathrm{kN})\end{array}$ & $\begin{array}{c}\text { Discrepancy } \\
(\%)\end{array}$ \\
\hline No defect & Perfect model & 10.69 & - & 0.154 & - \\
\hline \multirow{5}{*}{$5 \times 5 \mathrm{~mm}^{2}$} & Local delamination & 10.24 & -4.21 & 0.152 & -1.29 \\
\hline & Heterogeneity, 1.2 times* & 10.75 & 0.56 & 0.157 & 1.94 \\
\hline & Heterogeneity, 0.8 times* & 10.58 & -1.02 & 0.151 & -1.94 \\
\hline & Heterogeneity, 0.6 times* & 10.51 & -1.68 & 0.151 & -1.94 \\
\hline & Heterogeneity, 0.4 times* & 10.44 & -2.33 & 0.151 & -1.94 \\
\hline \multirow{3}{*}{$8 \times 8 \mathrm{~mm}^{2}$} & Local delamination & 9.61 & -10.10 & 0.143 & -7.14 \\
\hline & Heterogeneity, 1.2 times* & 10.90 & 1.96 & 0.157 & 1.94 \\
\hline & Heterogeneity, 0.8 times* & 10.46 & -2.15 & 0.15 & -2.59 \\
\hline \multirow{3}{*}{$10 \times 10 \mathrm{~mm}^{2}$} & Local delamination & 9.04 & -15.43 & 0.131 & -14.93 \\
\hline & Heterogeneity, 1.2 times* & 11.02 & 3.08 & 0.159 & 3.24 \\
\hline & Heterogeneity, 0.8 times* & 10.35 & -3.18 & 0.1511 & -1.88 \\
\hline \multirow{3}{*}{$12 \times 12 \mathrm{~mm}^{2}$} & Local delamination & 8.30 & -22.35 & 0.124 & -19.48 \\
\hline & Heterogeneity, 1.2 times* & 11.16 & 4.39 & 0.161 & 4.54 \\
\hline & Heterogeneity, 0.8 times* & 10.21 & -4.49 & 0.147 & -4.54 \\
\hline
\end{tabular}

* Of original material properties 


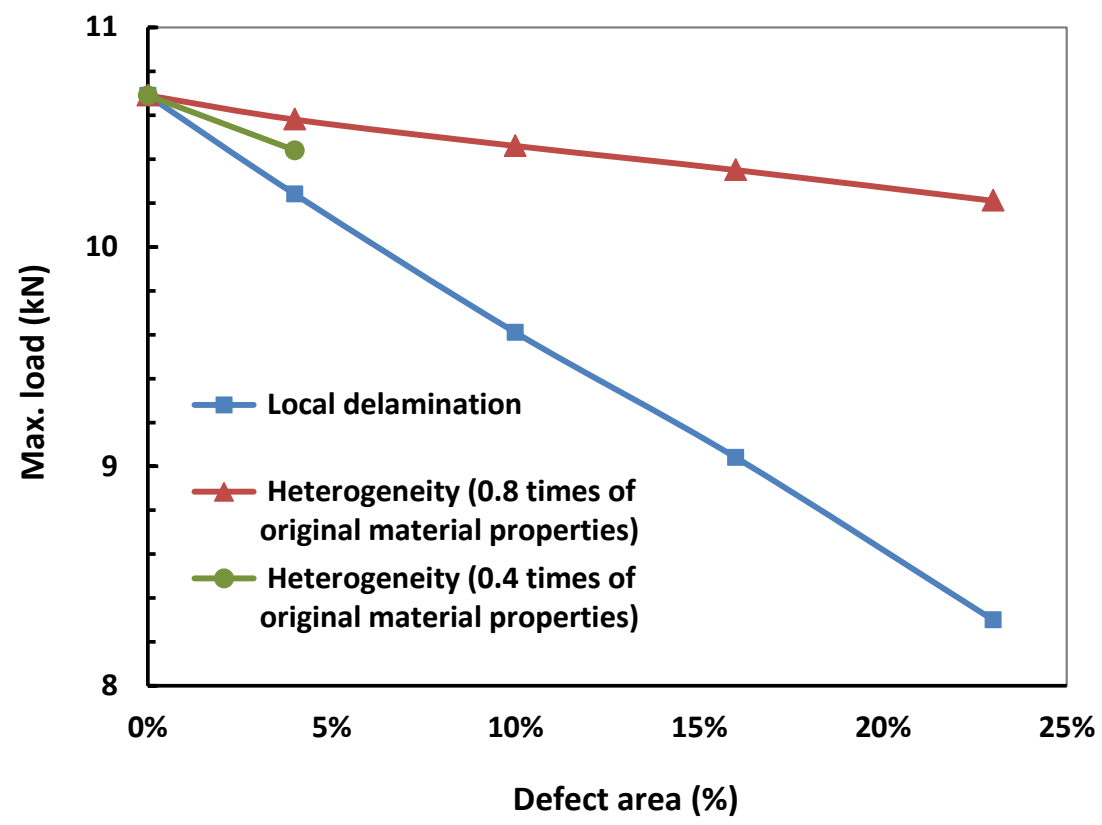

Fig. 11 The influence of defect area on the maximum load predicted numerically for the araldite 2015 .

\subsection{Stress analysis of adhesive joint}

The von-Misses stress distribution at maximum load for square shapes of $0.5 \times 0.5 \mathrm{~mm}^{2}$ area defect is presented in Fig. 12. Nevertheless, stress fields in every faulty specimen almost remain intact compared to perfect adhesive bond, but as the adhesive bond strength decreases, the stress values are decreasing in adherends. Accordingly, peel (direct through-thickness) stress at maximum load in the adhesive layer for square shapes of $0.5 \times 0.5 \mathrm{~mm}^{2}$ area defect is shown in Fig. 13. Additionally, there is a sudden change in stress fields in 13-c and 13-f at the center of adhesive layer which are on behalf of 1.2 times material properties and delamination, respectively. Stress concentration at the top and bottom of delaminated specimen which present defect is much more severe than other specimens and at overall delaminated specimen has the lowest value of stress. Due to the severe stress concentration and sudden change of stress fields in the model with delamination, peel stress at different size of delamination is presented in Fig. 14. Because of adhesive absence at the center of overlap area, induced stress increases with enhancing the size of delamination which applies to adherends. Also, observing Fig. 15, distinguishes induced stress to the adhesive layer for a delaminated model, there is a significant stress concentration at the top and bottom of delamination location and it becomes more intense with increasing the size of delamination. Consequently, Transverse shear stresses $\left(t_{x z}\right.$ and $\left.t_{y z}\right)$ in adhesive layer are shown in Figs. 16 and 17. It can be seen from Fig. 16, that, 1.2 times material properties has more stress than perfect model at heterogeneous location, also at 0.8 to 0.4 times material properties stress value decreases at heterogeneous location, delaminated specimen shows the lowest value at delamination location which applies to adherend due to the lack of adhesive. In Fig. 17 for $t_{y z}$ there is same condition like Fig. 16. However, for the model with delamination (Fig. 17 (f)) there is a stress concentration at the top and down of delamination location. 


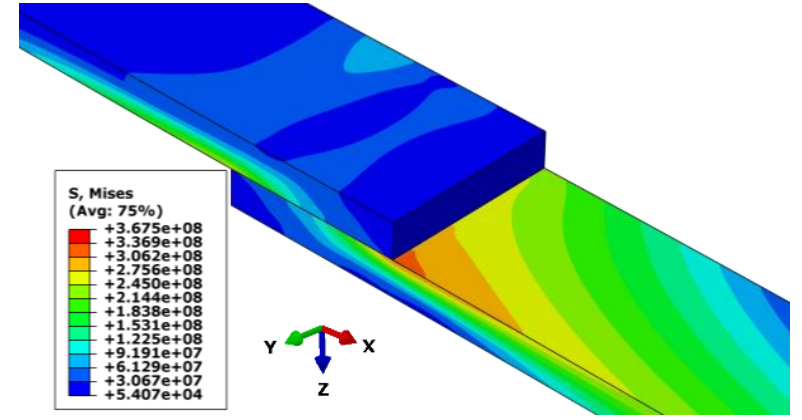

(a)

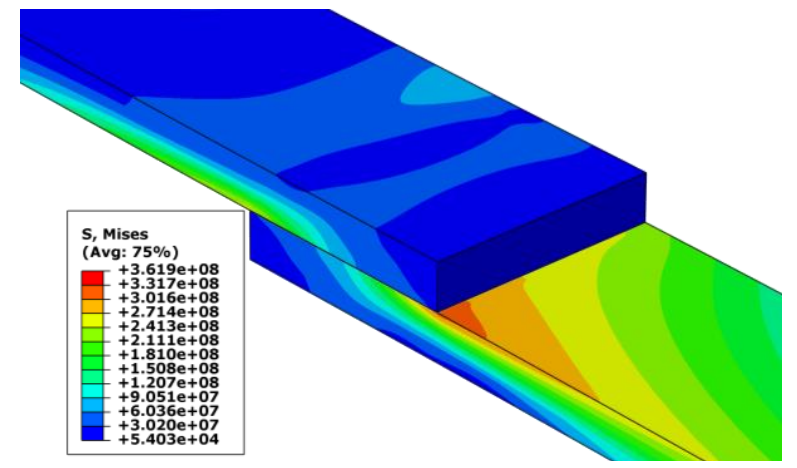

(c)

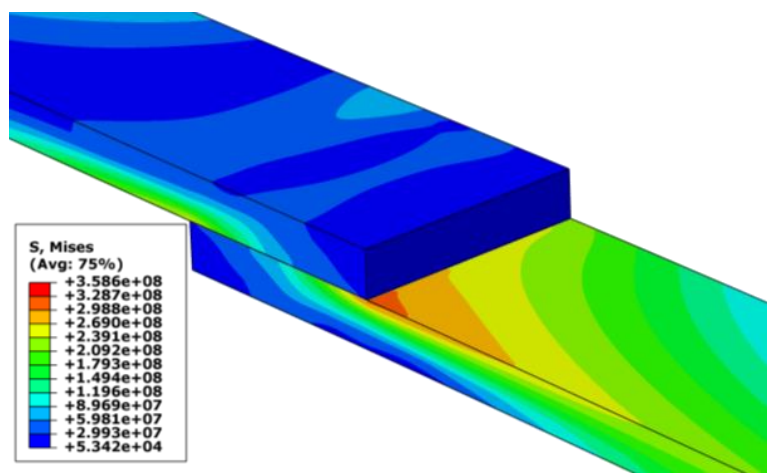

(e)

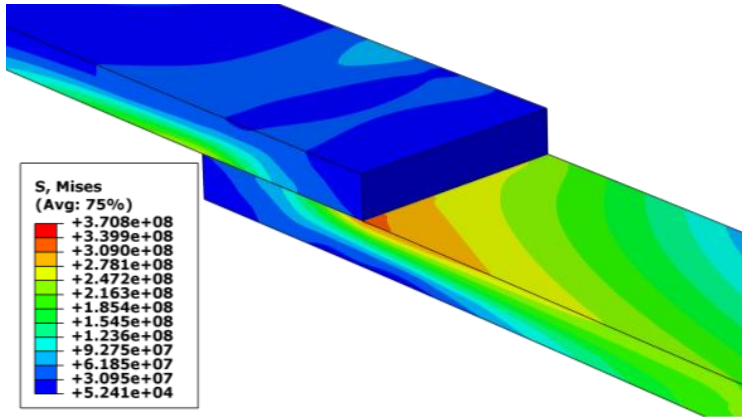

(b)

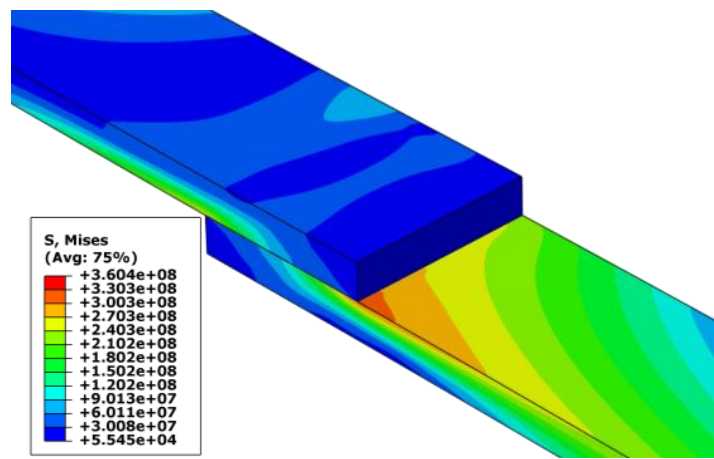

(d)

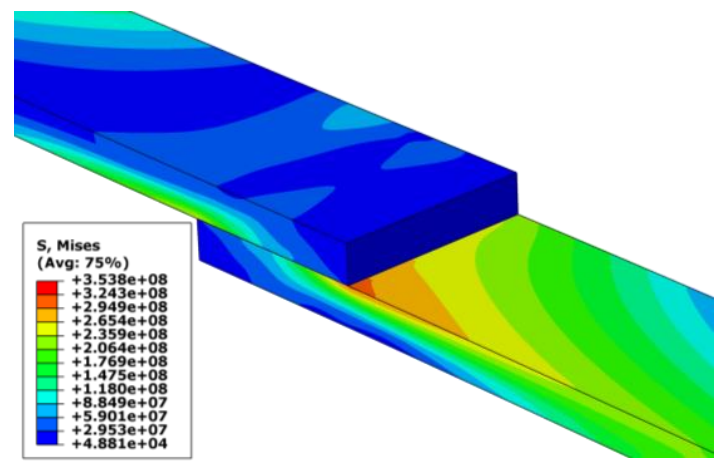

(f)

Fig. 12 Von-Misses stress fields at maximum load in adherends for (a) perfect single lap-joint and (b) square shapes $0.5 \times 0.5 \mathrm{~mm}^{2}$ defect as 1.2 times of cohesive strength and critical energy release rates, (c) 0.8 times of cohesive strength and critical energy release rates (d) 0.6 times of cohesive strength and critical energy release rates, (e) 0.4 times of cohesive strength and critical energy release rates and (f) defect in the form of delamination. 


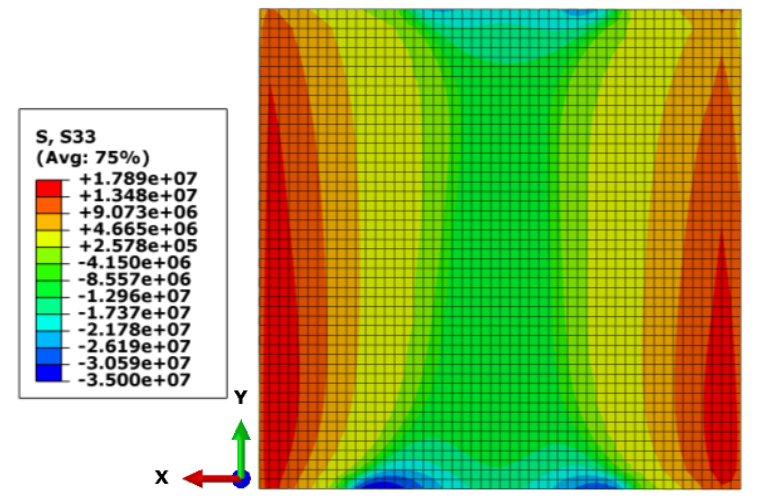

(a)

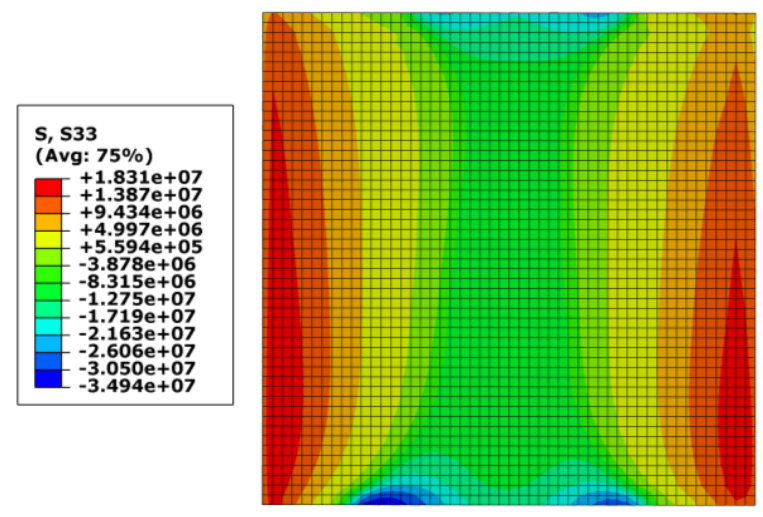

(c)

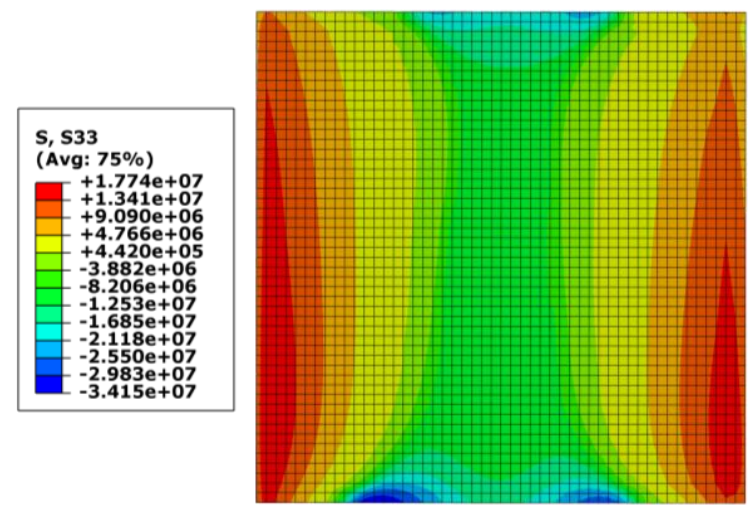

(e)

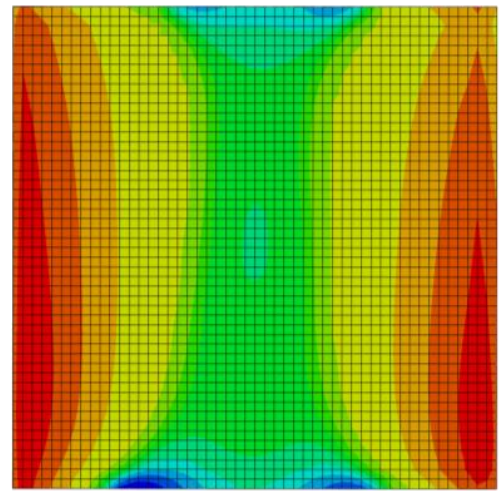

(b)

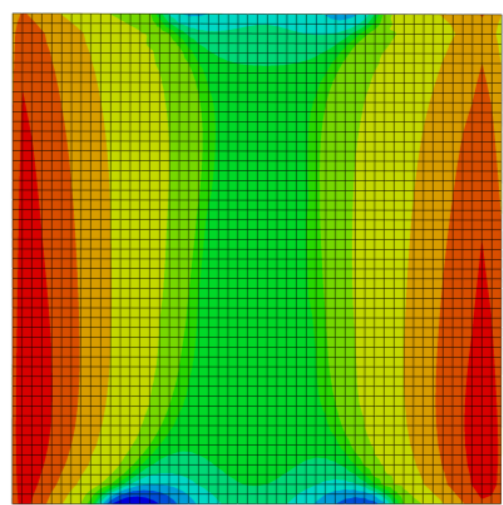

(d)

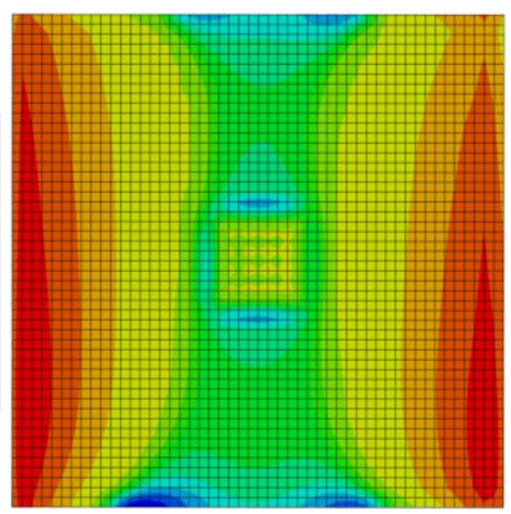

(f)

Fig. 13 Peel (direct through-thickness) stress fields at maximum load in overlap area adhesive for (a) perfect single lap-joint and (b) square shapes $0.5 \times 0.5 \mathrm{~mm}^{2}$ heterogeneity as 1.2 times of cohesive strength and critical energy release rates, (c) 0.8 times of cohesive strength and critical energy release rates, (d) 0.6 times of cohesive strength and critical energy release rates, (e) 0.4 times of cohesive strength and critical energy release rates and (f) inclusion in the form of delamination. 


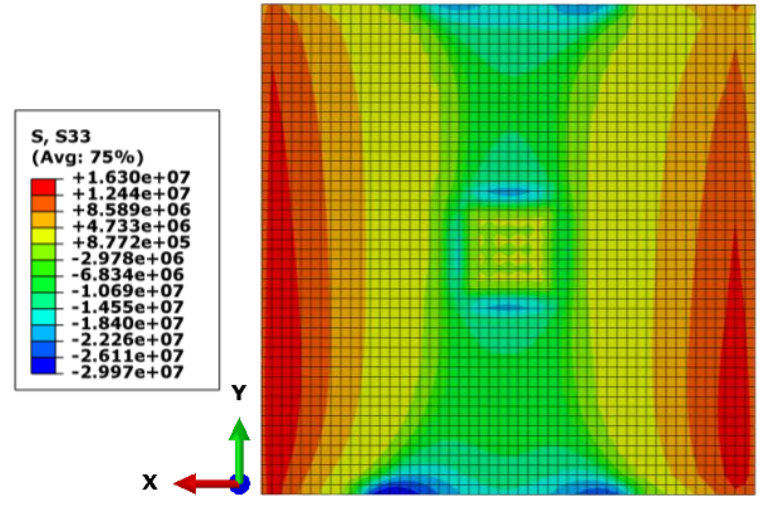

(a)

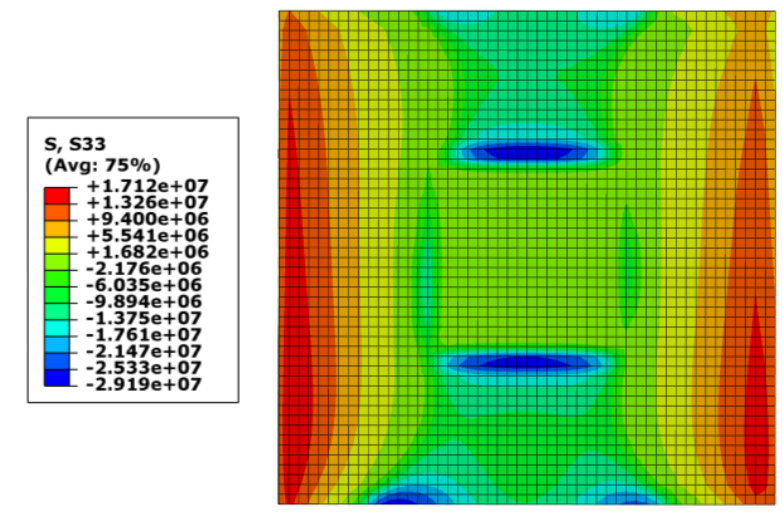

(c)
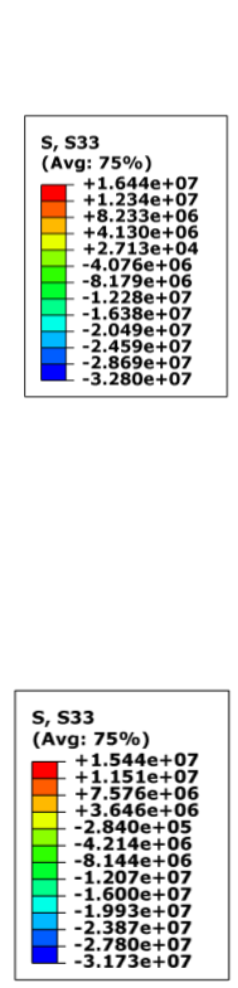

Fig. 14 Peel (direct through-thickness) stress fields at maximum load in overlap area adhesive for (a) $0.5 \times 0.5 \mathrm{~mm}^{2}$, (b) $0.8 \times 0.8 \mathrm{~mm}^{2}$, (c) $10 \times 10 \mathrm{~mm}^{2}$ and (d) $12 \times 12 \mathrm{~mm}^{2}$ delamination.

\section{Induced Stress to Adherend}
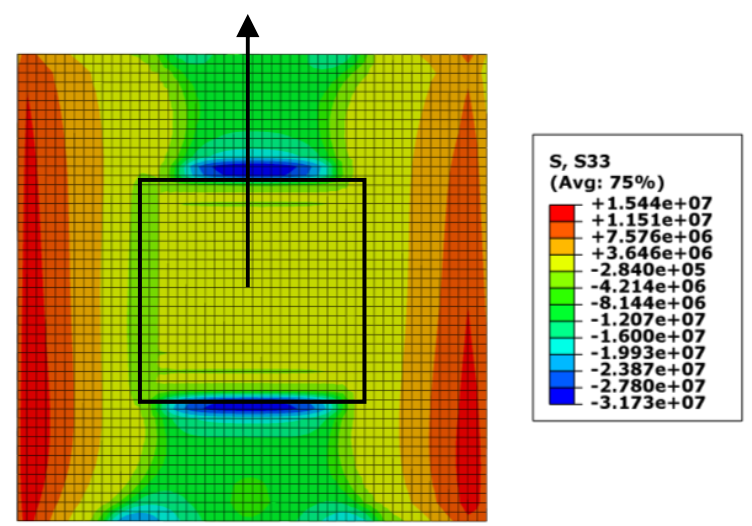

Fig. 15 Peel (direct through-thickness) stress fields at maximum load for $12 \times 12 \mathrm{~mm}^{2}$ delamination in overlap area and adhesive layer. 


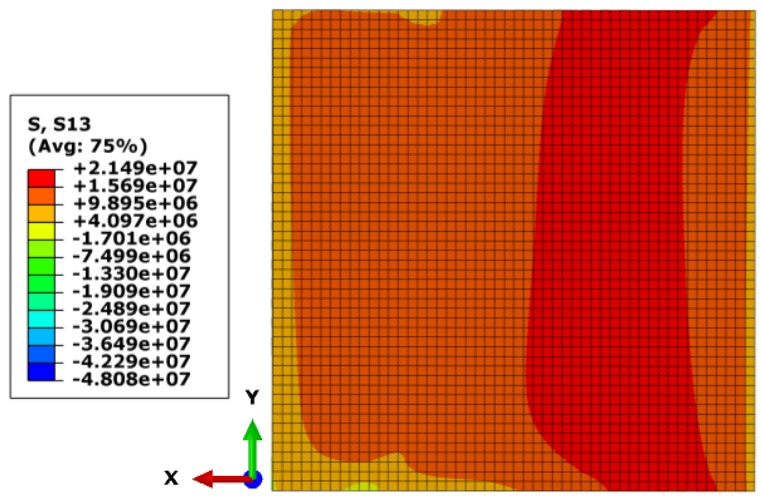

(a)

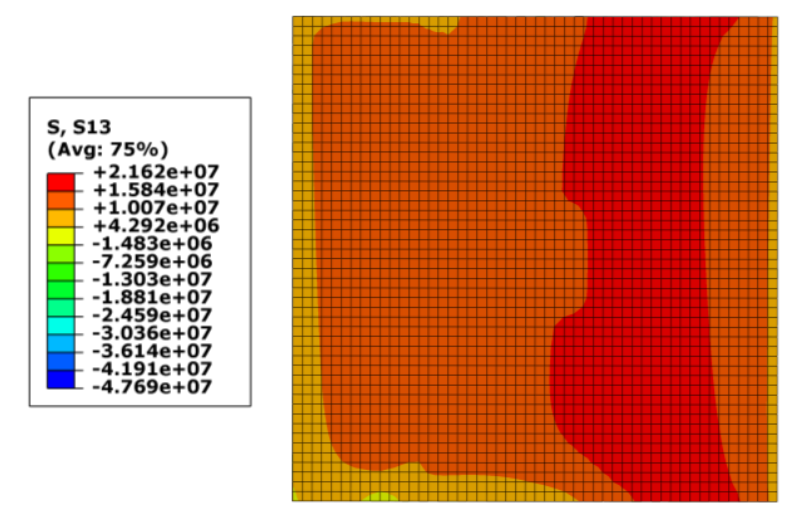

(c)

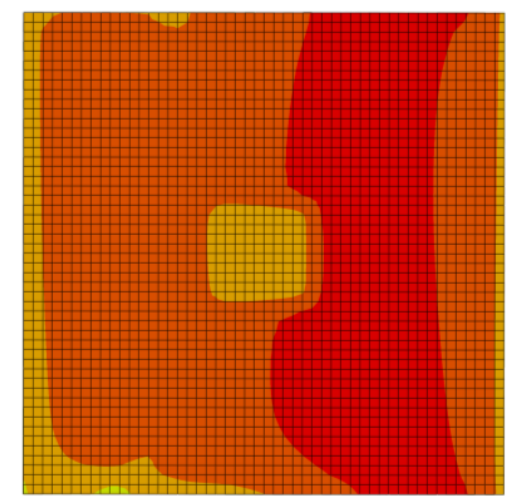

(e)
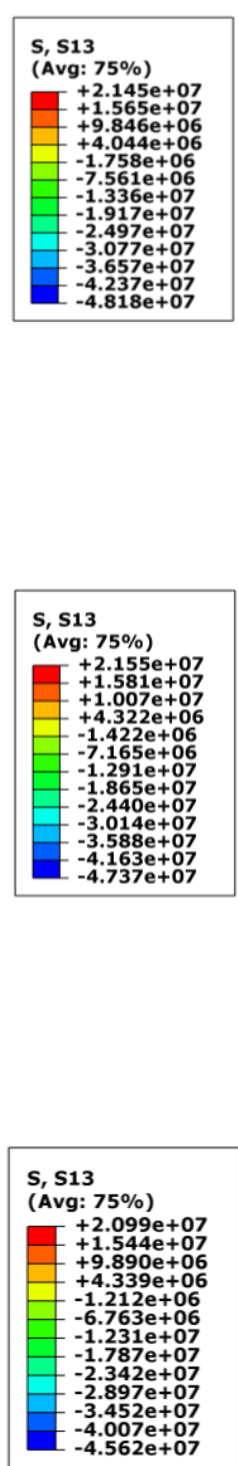

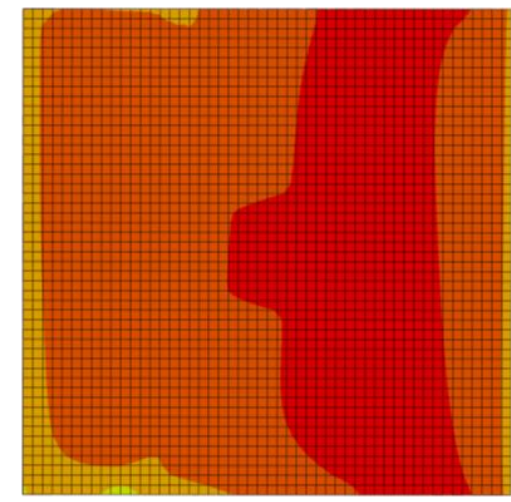

(b)

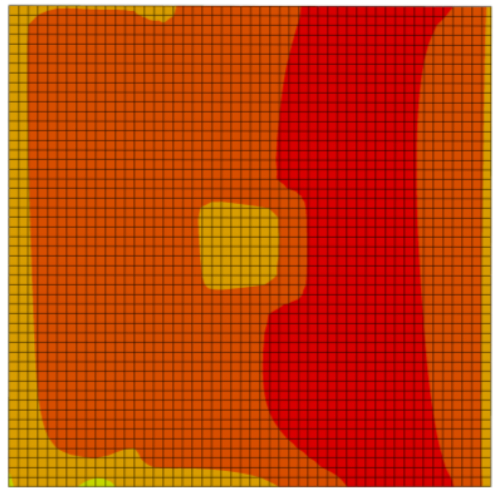

(d)

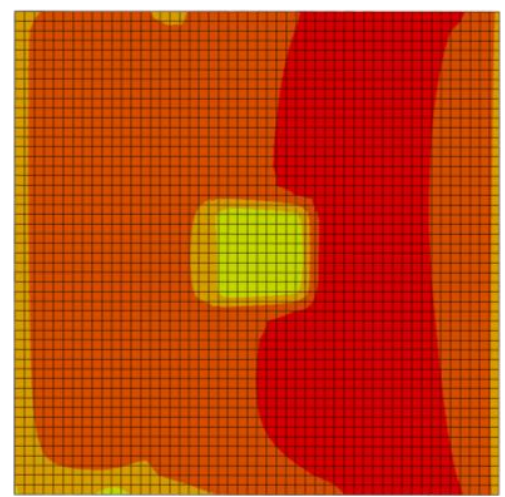

(f)

Fig. 16 Transverse shear $\left(t_{x z}\right)$ stress fields at maximum load in overlap area adhesive for (a) perfect single lap-joint and (b) square shapes $0.5 \times 0.5 \mathrm{~mm}^{2}$ defect as 1.2 times of cohesive strength and critical energy release rates, (c) 0.8 times of cohesive strength and critical energy release rates, (d) 0.6 times of cohesive strength and critical energy release rates, (e) 0.4 times of cohesive strength and critical energy release rates and (f) defect in the form of delamination. 


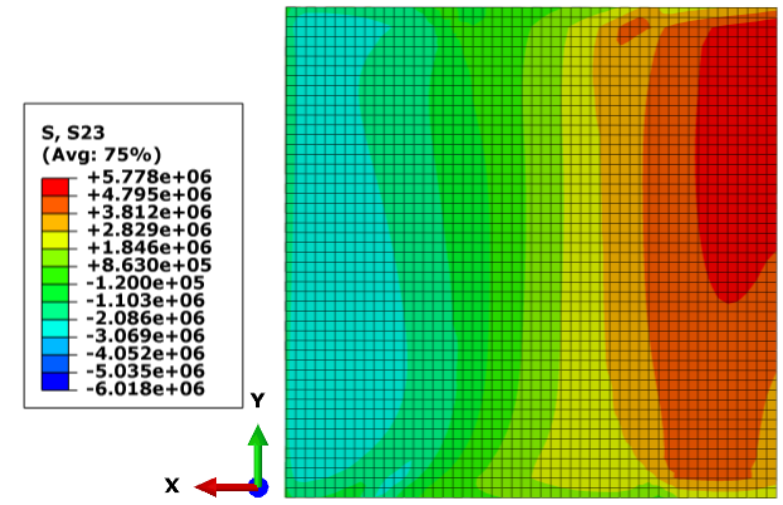

(a)

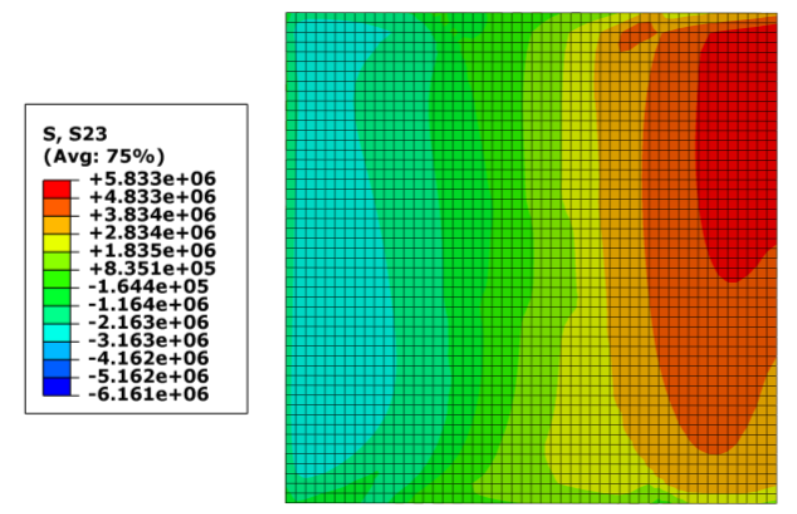

(c)

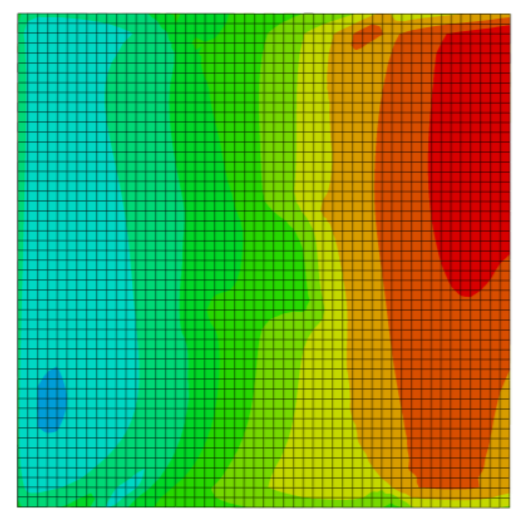

(e)
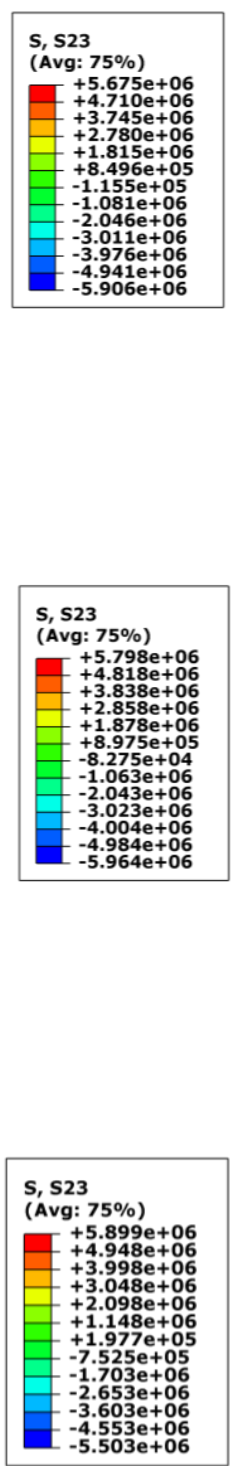

(f)

Fig. 17 Transverse shear $\left(t_{y z}\right)$ stress fields at maximum load in overlap area adhesive for (a) perfect single lap-joint and (b) square shapes $0.5 \times 0.5 \mathrm{~mm}^{2}$ defect as 1.2 times of cohesive strength and critical energy release rates, (c) 0.8 times of cohesive strength and critical energy release rates (d) 0.6 times of cohesive strength and critical energy release rates, (e) 0.4 times of cohesive strength and critical energy release rates and (f) defect in the form of delamination.

\section{CONCLUSION}

Defect has great impact in material performance since it changes material integrity. Because of obscurity in material performance, study of defect effects in adhesive layer is an important issue. This work aimed the evaluation of defect effect in strength of adhesive joint using a bilinear CZM, by approximating the behaviour of a single lap-joint after validation of the model with experiments. Initially after presenting the mathematical relations required for initiation and developing of damage based on bilinear mixed-mode CZM, a 3D finite element 
model of a single lap-joint is constructed for validation purpose. Linear field and strength prediction of current model are found very desirable however; there is a variation in amount of maximum displacement and predicting softening behaviour, which result from numerical limitation of CZM law shape. Nevertheless, overall accuracy of present numerical prediction is pleasant. Finally, defects are imported to model in the form in two different types (1) locally inadequate bonding which is modelled as change of the adhesive properties like cohesive strength and critical energy release rates and (2) void/inclusion which is considered as local delamination in different sizes respectively. Joint strength is investigated in four different size of defect in the shape of square area at the center of joint's overlap area for presenting defects. Eventually, stress fields is calculated for adhesive layer and adherends. Present investigation shows that, defect has significant impact on the results. Results show that with taking defect into account, strength of bonded joint changes and as the size of defect increases the joint strength changes more severe. It is found that heterogeneity as degraded material properties and delamination weaken joint strength. Moreover, heterogeneity as raised material properties predicts joint's strength more than perfect model. At constant size of defect, delamination has weakened the bonded joint strength, and the weakening is about 5\% to $23 \%$ at smallest and largest size respectively. Calculating stress fields in adherends shows that stress fields does not change in adherends, however, stress reduced with reduction of joint's strength. By evaluating peel stress in adhesive layer, it is found that there is a sudden change of stress fields for raised material properties (Heterogeneous model) at the center of adhesive layer. Whereas, there is a significant stress concentration in the delaminated adhesive layer and it becomes more severe with enlarging the size of defect. Examining transverse shear stresses $\left(t_{x z}\right.$ and $\left.t_{y z}\right)$ show that one of shear stresses $\left(t_{x z}\right)$ affected by both type of defects same, however other shear stress $\left(t_{y z}\right)$ is more affected by delamination since there is a stress concentration.

\section{REFERENCES}

[1] M. J. Lee, T. M. Cho, W. S. Kim, B. C. Lee, J. J. Lee. Determination of cohesive parameters for a mixed-mode cohesive zone model. International Journal of Adhesion and Adhesives 2010 (30), No. 5, pp. 322-328.

[2] Y. H. Lai, M. D. Rakestraw, D. A. Dillard. The cracked lap shear specimen revisited-a closed form solution. International Journal of Solids and Structures 1996 (33), No. 12, pp. 1725-1743.

[3] M. Goland, E. Reissner. The stresses in cemented joints. Journal of Applied Mechanics 1944 (66), pp. 17-27.

[4] F. Szepe. Strength of adhesive-bonded lap joints with respect to change of temperature and fatigue. Experimental Mechanics 1966 (6), No. 5, pp. 280-286.

[5] L. J. Hart-Smith. Adhesive-bonded single-lap joints. NASA Technical Report CR112236. Hampton, USA: Langley Research Centre, 1973.

[6] J. Pirvics. Two dimensional displacement-stress distributions in adhesive bonded composite structures. Journal of Adhesion 1974 (6), No. 3, pp. 207-228.

[7] S. K. Panigrahi, B. Pradhan. Three dimensional failure analysis and damage propagation behavior of adhesively bonded single lap joints in laminated FRP composites. Journal of Reinforced Plastics and Composites 2007 (26), No. 2, pp. 183-201.

[8] M. Venkateswara Rao, K. Mohana Rao, V. Rama Chandra Raju, V. Bala Krishna Murthy, V. V. Sridhara Raju. Three-dimensional finite element analysis of adhesively bonded single lap joints in laminated FRP composites subjected to combined loading 
with C-F end conditions. Journal of Mechanical Engineering - Strojnícky časopis 2009 (60), No. 5-6, pp. 277-288.

[9] G. R. Wooley, D. R. Carver. Stress concentration factors for bonded lap joint. Journal of Aircraft 1971 (8), pp. 817-820.

[10] M. Y. Tsai, J. Morton. An evaluation of analytical and numerical solutions to the singlelap joint. International Journal of Solids and Structures 1994 (31), No. 18, pp. 25372563.

[11] L. F. M. Da Silva, R. D. S. G. Campilho. Advances in Numerical Modelling of Adhesive Joints. Heidelberg, Springer, 2011.

[12] R. D. S. G. Campilho, M. D. Banea, J. A. B. P. Neto, L. F. M. Da Silva. Modelling adhesive joints with cohesive zone models: effect of the cohesive law shape of the adhesive layer. International Journal of Adhesion and Adhesives 2013 (44), pp. 48-56.

[13] R. D. S. G. Campilho, M. F. S. F. De Moura, A. M. J. P. Barreto, J. J. L. Morais, J. J. M. S. Domingues. Fracture behaviour of damaged wood beams repaired with an adhesively-bonded composite patch. Composites Part A: Applied Science and Manufacturing 2009 (40), No.6-7, pp. 852-859.

[14] P. B. Woelke, M. D. Shields, N. N. Abboud, J. W. Hutchinson. Simulations of ductile fracture in an idealized ship grounding scenario using phenomelogical damage and cohesive zone models. Computational Materials Science 2013 (80), pp. 79-95.

[15] R. D. S. G. Campilho, M. D. Banea, J. A. B. P. Neto, L. F. M. Da Silva. Modelling of single-lap joints using cohesive zone models: effect of the cohesive parameters on the output of the simulations. Journal of Adhesion 2012 (88), No. 4-6, pp. 513-533.

[16] R. D. S. G. Campilho, M. F. S. F. De Moura, D. A. Ramantani, J. J. L. Morais, J. J. M. S. Domingues. Buckling behaviour of carbon-epoxy adhesively-bonded scarf repairs. Journal of Adhesion Science and Technology 2009 (23), No. 10-11, pp. 1493-1513.

[17] M. M. Abou-Hamda, M. M. Megahed, M. M. I. Hammouda. Fatigue crack growth in double cantilever beam specimen with an adhesive layer. Engineering Fracture Mechanics 1998 (60), No. 5-6, pp. 605-614.

[18] R. D. S. G. Campilho, T. A. B. Fernandes. Comparative evaluation of single-lap joints bonded with different adhesives by cohesive zone modelling. Procedia Engineering 2015 (114), pp. 102-109.

[19] G. Mancusi, F. Ascione. Performance at collapse of adhesive bonding. Composite Structures 2013 (96), pp. 256-261.

[20] E. F. Karachalios, R. D. Adams, L. F. M. Da Silva. Strength of single lap joints with artificial defects. International Journal of Adhesion and Adhesives 2013 (45), pp. 6976.

[21] V. A. Maksimyuk, E. A. Storozhuk, I. S. Chernyshenko. Nonlinear deformation of thin isotropic and orthotropic shells of revolution with reinforced holes and rigid inclusions. International Applied Mechanics 2013 (49), No. 6, pp. 685-692.

[22] V. N. Chekhov, S. V. Zakora. Stress concentration in a transversely isotropic spherical shell with two circular rigid inclusions. International Applied Mechanics 2011 (47), pp. 441-448. 
[23] I. S. Chernyshenko. Nonlinear deformation of isotropic and orthotropic shells with holes reinforced by a rigid elastic element. International Applied Mechanics 1989 (25), No. 1, pp. 54-59.

[24] V. P. Shevchenko, S. V. Zakora. On the mutual influence of closely located circular holes with rigid contours in a spherical shell. Journal of Mathematical Sciences 2011 (174), pp. 322-330.

[25] S. V. Zakora, V. N. Chekhov. Stress state of a transversely isotropic spherical shell with a rigid circular inclusion. International Applied Mechanics 2005 (41), No. 12, pp. 13841390 .

[26] J. D. Engerer, E. Sancaktar. The effects of partial bonding in load carrying capacity of single lap joints. International Journal of Adhesion and Adhesives 2011 (31), No. 5, pp. 373-379.

[27] N. G. Berry, J. R. M. D'Almeida. The influence of circular centered defects on the performance of carbon-epoxy single lap joints. Polymer Testing 2002 (21), No. 4, pp. 373-379.

[28] J. H. Park, J. H. Choi, J. H. Kweon. Evaluating the strengths of thick aluminumtoaluminum joints with different adhesive lengths and thicknesses. Composite Structures 2010 (92), No. 9, pp. 2226-2235.

[29] T. T. Wang, F. W. Ryan, H. Schonhorn. Effect of bonding defects on shear strength in tension of lap joints having brittle adhesives. Journal of Applied Polymer Science 1972 (16), No. 8, pp. 1901-1909.

[30] M. Olia, J. N. Rossettos. Analysis of adhesively bonded joints with gaps subjected to bending. International Journal of Solids and Structures 1996 (33), No. 18, pp. 26812693.

[31] A. Chadegani, R. C. Batra. Analysis of adhesive-bonded single-lap joint with an interfacial crack and a void. International Journal of Adhesion and Adhesives 2011 (31), No. 6, pp. 455-465.

[32] M. U. Uysala, U. Güvena. Bonded plate having orthotropic inclusion in adhesive layer under in-plane shear loading. Journal of Adhesion 2016 (92), No. 3, pp. 214-235.

[33] L. Prasad, R. Khantwal. Study on breaking load of single lap joint using hybrid joining techniques for alloy steel AISI 4140 and mild steel: Taguchi and neural network approach. Journal of Mechanical Engineering - Strojnicky časopis 2018 (68), No. 1, pp. $51-60$.

[34] Abaqus 6.13 Analysis User's Manual, 2012, Simulia. Dassault Systèmes.

[35] A. Turon, C. G. Dávila, P. P. Camanho, J. Costa. An engineering solution for using coarse meshes in the simulation of delamination with cohesive zone models. NASA Technical Memorandum, Technical Report, NASA/TM-2005-213547, L-19109, 2005.

[36] A. Corigliano. Formulation, identification and use of interface models in the numerical analysis of composite delamination. International Journal of Solids and Structures 1993 (30), No. 20, pp. 2779-2811.

[37] P. P. Camanho, C. Davila, M. De Moura. Numerical simulation of mixed-mode progressive delamination in composite materials. Journal of Composite Materials 2003 (37), No. 16, pp. 1415-1438. 
[38] P. W. Harper, S. R. Hallett. Cohesive zone length in numerical simulations of composite delamination. Engineering Fracture Mechanics 2008 (75), No. 16, pp. 4774-4792.

[39] M. L. Benzeggagh, M. Kenane. Measurement of mixed-mode delamination fracture toughness of unidirectional glass/epoxy composites with mixed-mode bending apparatus. Composites Science and Technology 1996 (56), No. 4, pp. 439-449.

[40] K. N. Anyfantis, N. G. Tsouvalis. A 3D ductile constitutive mixed-mode model of cohesive elements for the finite element analysis of adhesive joints. Journal of Adhesion Science and Technology 2013 (27), No. 10, pp. 1146-1178.

[41] K. N. Anyfantis, N. G. Tsouvalis. A novel traction-separation law for the prediction of the mixed mode response of ductile adhesive joints. International Journal of Solids and Structures 2012 (49), No. 1, pp. 213-226. 